\title{
Análise morfológica da corrosão por pites em aço inoxidável austenítico AISI 310S submetido à exposição em névoa salina
}

\author{
RIBEIRO $^{\text {IIIII }}$, R.B.; CODARO ${ }^{\text {II }}$, E.N.; HEIN ${ }^{\mathrm{II}}$, L.R.O.; ROSA ${ }^{\mathrm{I}, \mathrm{III}}$, J.L.' MARIOTTO ${ }^{\mathrm{III}}$, S.F.F.; MERAZ ${ }^{\mathrm{IV}}$, E.A.

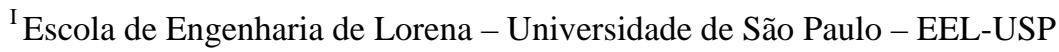 \\ Pólo Urbo Industrial Gleba AI-6, Bairro do Mondesir, Lorena, SP, CEP 12600-000 \\ email: ispic@fatea.br \\ ${ }^{\text {II }}$ Faculdade de Engenharia de Guaratinguetá - Universidade Estadual Paulista - FEG-UNESP \\ Avenida Dr. Ariberto Pereira da Cunha, 333, Guaratinguetá, SP, CEP:12.516-410 \\ email: codaro@feg.unesp.br, rhein@feg.unesp.br \\ III Faculdades Integradas Teresa D`Ávila - FATEA - SALESIANAS \\ Avenida Peixoto de Castro, 539, Lorena, SP, CEP 12606-580 \\ email: jlrosa@demar.eel.usp.br, sabrinamariotto@yahoo.com.br \\ IV Division Académica de Ingeniería y Arquitectura - Universidad Juárez Autonoma Tabasco - UJAT \\ Km 1, Carretera Cunduacan - Jalpa Mendez - Cunduacan - Tabasco - CP 86690 - México \\ email: bellitadelangel@gmail.com
}

\begin{abstract}
RESUMO
O artigo teve como objetivo estudar a evolução do crescimento, distribuição e classificação dos pites em aços inoxidáveis austeníticos AISI 310S no estado como recebida e tratado termicamente, submetidos a diferentes tempos de exposição em meio salino. A aplicabilidade deste trabalho baseou-se no desenvolvimento de uma técnica para caracterização morfológica da corrosão localizada, associado com os aspectos de descrição de formas, tamanho, parâmetros específicos e populacionais. A metodologia consistiu nas seguintes etapas: preparação dos corpos de prova, testes de corrosão via névoa salina em diferentes condições, análise microestrutural, análise dos perfis dos pites, processamento digital e análise de imagens, visando caracterizar a distribuição, morfologia e o tamanho dos pites. Os resultados obtidos no processamento digital e análise de imagens dos perfis foram submetidos á análise estatística, utilizando à mediana como parâmetro de avaliação na liga como recebido e tratada. A liga como recebido, exibe a seguinte morfologia: pites hemisféricos $>$ região de transição $\mathrm{A}>$ região de transição $\mathrm{B}>$ irregulares> cônicos. A quantidade de pites na liga tratada a cada tempo de exposição é: região de transição B> hemisféricos> região de transição A> cônicos> irregulares.
\end{abstract}

Palavras-chave: Corrosão por pites, aço inoxidável austenítico, névoa salina, análise de imagens, microestrutura.

\section{Morphological analysis of pitting corrosion in AISI 310S austenitic stainless steel after salt spray exposition}

\begin{abstract}
This paper aims to study evolution of increase, distribution and classification of pits in 310S austenitic stainless steels obtained in the state as-received and heat-treated under different exposure times in saline. This work applicability has been based on a technique development for morphologic characterization of localized corrosion associated with description aspects of shapes, size and population-specific parameters. Methodology has been consisted in the following steps: specimens preparation, corrosion tests via salt spray in different conditions, microstructural analysis, pits profiles analysis and images analysis, digital processing and image analysis in order to characterize the pits distribution, morphology and size. Results obtained in digital processing and profiles image analysis have been subjected to statistical analysis using median as parameter in the alloy as received and treated.The alloy as received displays the following morphology: hemispheric pits> transition region $\mathrm{A}>$ transition region $\mathrm{B}>$ irregular $>$ conic. The pits amount in the treated alloy at each exposure time is: transition region $\mathrm{B}>$ hemispherical $>$ transition region $\mathrm{A}>$ conic $>$ irregular.
\end{abstract}

Key-Words: Corrosion Pitting, austenitic stainless steel, salt spray, image analysis, microstructure 


\section{INTRODUÇÃO}

A corrosão nos materiais apresenta-se de diferentes formas variando da condição uniforme até a localizada, sendo que esta última é evidenciada pela maneira mais perigosa de ataque por meio da dissolução local, afetando pequenas áreas e contribuindo para o aceleramento da corrosão metálica. Isso resulta na formação de cavidades, defeitos, irregularidades, sulcos, relevos e poros na superfície, promovendo a formação de trincas e falhas nos produtos [1-2].

A inspeção visual ou a medida de perda de massa não são técnicas apropriadas para quantificação e a qualificação dos materiais que apresentam corrosão localizada em diferentes ambientes, principalmente os mais resistentes como: aços carbono, aços inoxidáveis, titânio, níquel, cobre, alumínio e suas ligas []].

Este método apresentou-se eficiente em materiais industriais que possuem tendência a sofrer corrosão localizada, especialmente por pites como as ligas de alumínio das séries 2xxx e 7xxx e Ti-6Al-4V em diferentes condições, com alta e baixa densidade de pites [4].

A morfologia e a classificação dos pites vem sendo estudadas por diversos pesquisadores e a cada vez mais em materiais estruturais como os aços inoxidáveis, titânio e alumínio e suas ligas em que são solicitados e aplicados em situações severas [5].

Para o desenvolvimento deste trabalho, buscou-se avaliar a aplicabilidade da técnica aplicando ferramentas operacionais de processamento digital e análise de imagens no aço inoxidável ABNT 310S no estado como recebido e tratado termicamente. A proposta deste artigo foi estudar a evolução temporal que reside o crescimento dos pites, bem como a classificação e distribuição morfológica, por meio de dados estatísticos descritivos (mediana) relacionando com as mudanças microestruturais e sua composição química, após serem submetidos a diferentes tempos de exposição em névoa salina [ㅁ-ㅁ].

\section{MATERIAIS E MÉTODOS}

O material empregado neste trabalho foi o aço inoxidável austenítico AISI 310S fornecido em forma de chapa de $10 \mathrm{~mm}$ e $6 \mathrm{~mm}$ de espessura no estado como recebida (laminado) e tratado termicamente à $620^{\circ} \mathrm{C}$ durante 24 horas, resfriado ao ar.

Os corpos de prova foram confeccionados nas dimensões 30mm x 25mm e preparados superficialmente com lixas de óxido de alumínio na seqüência: \#220-1500. Os testes de corrosão via névoa salina foram realizados no Laboratório Central da empresa TEKNO S.A., unidade de Guaratinguetá. As amostras foram submetidas a diferentes tempos de exposição como: 48, 120, 168, 216 e 312 horas.

A solução usada nos testes foi o cloreto de sódio ( $\mathrm{NaCl} 5 \%$ ) com $\mathrm{pH}$ 6,7 e a temperatura do processo controlada na ordem de $35^{\circ} \mathrm{C} \pm 1,7^{\circ} \mathrm{C}$, entretanto, a zona de exposição da cabine era totalmente fechada [్].

A composição química do material é apresentada na Tabela 1.

Tabela 1: Composição química do aço inoxidável ABNT 310S (\%)

\begin{tabular}{|l|l|l|l|l|l|c|}
\hline $\mathbf{C}$ & $\mathbf{S i}$ & $\mathbf{M n}$ & $\mathbf{C r}$ & $\mathbf{N i}$ & $\mathbf{N}$ & $\mathbf{F e}$ \\
\hline 0,05 & 0,56 & 1,28 & 24,0 & 19,39 & 0,10 & Remanescente \\
\hline
\end{tabular}

A caracterização microestrutural da liga baseou-se na preparação materialográfica clássica utilizando lixas d'água nas granulometrias \#220-4000 e o polimento com pasta de diamante de $3 \mu \mathrm{m}$ e $1 \mu \mathrm{m}$. Para a revelação microestrutural utilizou-se uma solução química com os seguintes reagentes: 10mL HF (48\%), 10mL $\mathrm{HNO}_{3}$ (65\%), 15mL HCl (35\%) e duas gotas de glicerol p.a, com objetivos de estudar a morfologia dos grãos e avaliar o tipo e a distribuição dos precipitados.

Foram realizados ensaios de microdureza Vickers utilizando o microdurômetro tipo MICROMET 2004, fabricado pela BULHER com carga de 100 gF e tempo de identação de 15 segundos numa superfície polida.

Os fatores que determinam o crescimento dos pites no aço inox ABNT 310S foram avaliados, por meio do seccionamento vertical, sobre baixa carga e rotação (ISOMET - 1000), em seguida o lixamento e polimento em nível metalográfico. Para assegurar a baixa deformação e a integridade da região do perfil e dos pites na superfície corroída durante o polimento mecânico empregou-se uma resina epóxis após o seccionamento e uma resina fenólica tipo baquelite para o embutimento. Os parâmetros morfológicos e microestruturais associados com suas mudanças foram caracterizados, logo após os testes de corrosão, por meio do processamento digital e análise de imagens baseado na microscopia óptica [10].

Foram avaliadas as características e as morfologias dos perfis dos pites no aço inox 310S, associando os dados estatísticos de posição e dispersão definindo os parâmetros de tamanho, descrição de forma e 
populacionais, aplicando os programas de domínio publico UTHSCSA IMAGE TOOL 3.0, IMAGE J e Media Cybernetics Image Pro plus 4.5/Materials - Pro Analyzer 3.1 realizados no LAIMat-DMT-FEG-UNESP.

A razão largura/profundidade, aqui denominada razão de aspecto e a retangularidade determinam exatamente os limites para a classificação geométrica dos pites individuais, pode ser observado no diagrama e representado pela Figura 1.

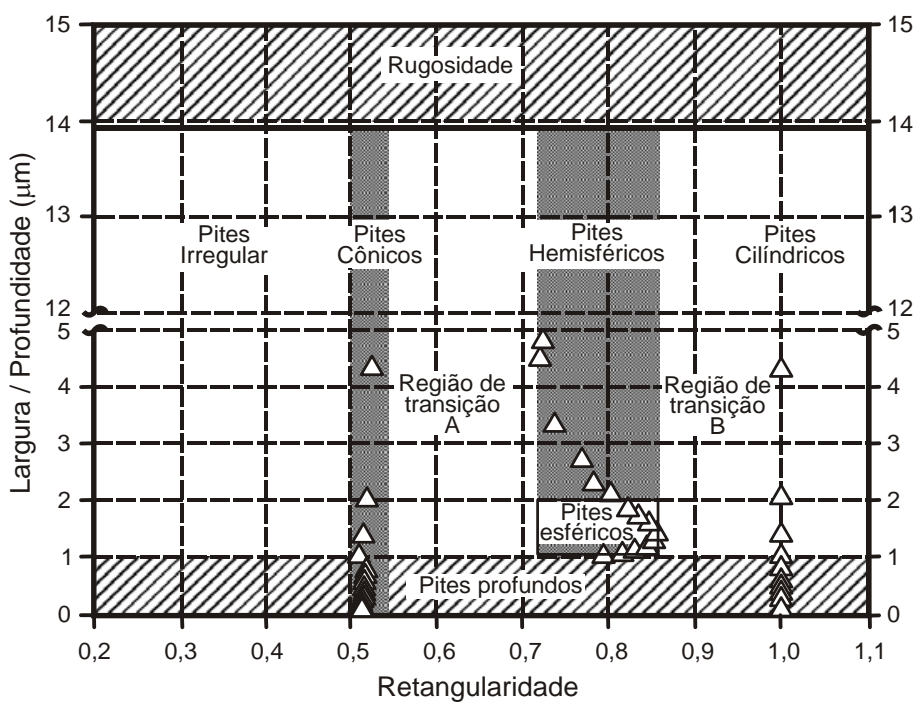

Figura 1: Diagrama para determinação dos objetos e a razão de aspecto da corrosão por pites nos materiais (Largura-Profundidade) versus retangularidade [11].

As faixas em cinza na Figura 1 correspondem ao espalhamento em relação aos valores teóricos de retangularidade devido à divisa das imagens em pixels, o que leva a uma distorção nos valores das áreas dos objetos para triângulos e círculos na avaliação dos resultados no processamento digital de imagens.

O diagrama para determinação dos objetos e a razão de aspecto da corrosão por pites nos materiais em função da retangularidade tem como objetivos gerais: (a) classificar a morfologia dos pites, (b) avaliar evolução que reside o crescimento dos pites e (c) comportamento morfológico do pites em relação a toda extensão (tempo de exposição) ao meio corrosivo.

Para os pites fechados e esféricos, a razão de aspecto é menor que 2 e a retangularidade ao redor de $\pi / 4$, os pites cilíndricos apresentam valores próximos de 1 , os cônicos individuais são mais alto na faixa 0.5 . Os pites hemisféricos possuem a razão de aspecto (largura/profundidade) acima de 2 , e a retangularidade ao redor de $\pi / 4$, os pites na geométrica irregular ou não definida apresentam valores menores que 0.5 para a retangularidade.

A região de transição A (pites quase-cônicos e/ou quase-hemisféricos) e B (pites quase-hemisféricos e/ou quase-cilíndricos) representa os pites que tenderam para geometria melhor definidas durante seu crescimento. Portanto, em materiais metálicos, a presença de defeitos superficiais (inclusões, trincas, microfraturas, precipitados etc.) favorece a nucleação dos pites em diferentes geometrias e induz a mudanças na cinética do sistema.

As diferentes geometrias estão relacionadas com a forma original desses defeitos. No entanto, durante o crescimento dos pites essas geometrias podem ser modificadas numa magnitude que dependerá do mecanismo de crescimento, microestrutura local e a natureza do ambiente corrosivo [11].

\section{RESULTADOS E DISCUSSÃO}

Para simplificar a análise dos resultados, a análise microestrutural, ensaios de microdureza, processamento digital e análise de imagens, a distribuição, morfologia e o tamanho dos pites foram analisados individualmente e posteriormente correlacionados. A verificação e a validação dos resultados obtidos no processamento digital e análise de imagens dos perfis, os dados foram submetidos á análise estatística, utilizando principalmente a mediana de cada parâmetro determinado na liga. O aço inox 310 S apresenta excelente resistência à corrosão metálica e à oxidação. As preocupações referentes, a sua utilização se relaciona com a susceptibilidade às formas, tais como: por pites e a intergranular [12]. 
A Figura 2 mostra a microestrutura na condição como recebida caracterizada por grãos de austenita tipicamente na forma de degraus, sendo que o nível de sensitização nesta condição é estimado a zero, nota-se a presença de regiões deformadas e o aumento nos valores da microdureza.

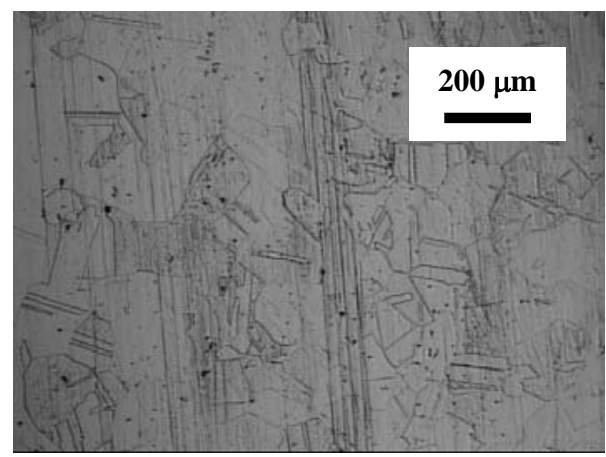

Figura 2: Micrografia do aço inoxidável 310S, no estado como recebida.

$\mathrm{Na}$ Figura 3, a amostra foi submetida ao tratamento térmico $620^{\circ} \mathrm{C}$ durante 24 horas, visualiza a microestrutura típica e de caráter original do aço inox praticamente sensitizado, resultando em contornos de grãos coalescidos com elevada precipitação de carbetos de cromo e na forma tipicamente de vala, devido alta fração volumétrica e o aumento na extensão dos contornos de grãos ocorridos pela presença de precipitados de carbetos de cromo.

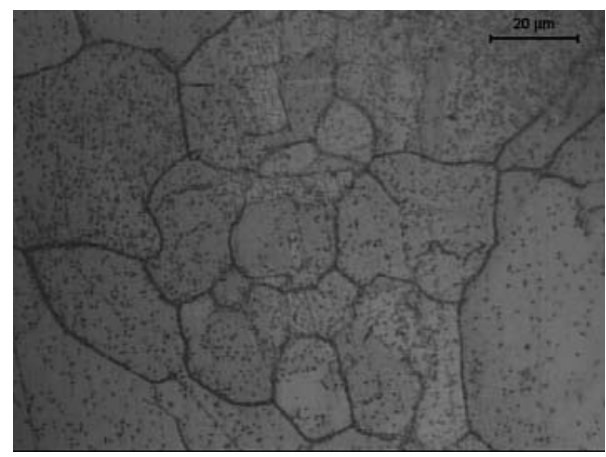

Figura 3: Micrografia do aço inoxidável 310S tratado a $620^{\circ} \mathrm{C}-24$ horas, resfriamento ao ar.

Os aços inoxidáveis solubilizadas e sensitizados apresentam fases e precipitados em diferentes formas geométricas, devido ao tempo de tratamento térmico, iniciando nos contornos de grão, contornos incoerentes de macla, contornos coerentes de macla, interior dos grãos e por último na movimentação das discordâncias nos sistemas de deslizamento [13-14].

Na Tabela 2, mostra que o material quando tratado os valores são menores na microdureza que o estado como recebido, motivado pela elevada taxa de deformação mecânica e sua composição química (material como recebido).

Tabela 2: Valores de Microdureza Vickers no aço inoxidável austenítico ABNT 310S

\begin{tabular}{|l|c|c|}
\hline \multicolumn{1}{|c|}{ Material } & Valores de Microdureza - HV & Desvio Padrão \\
\hline Tratada à $670^{\circ} \mathrm{C}-5$ horas, resfriado ao ar & 173,83 & 2,33 \\
\hline Como recebido & 219,95 & 3,09 \\
\hline
\end{tabular}

Os aços inoxidáveis possuem a tendência da formação do fenômeno de sensitização quando submetido às situações de trabalho em temperaturas acima de $600^{\circ} \mathrm{C}$, o que em sua microestrutura torna-se favorável à formação direta da precipitação de carbetos em diferentes morfologias, contribui significativamente para a corrosão por pites e intergranular no material.

As micrografias 4 (a) e (b) ilustram, a partir da microscopia óptica dos perfis, distintos mecanismos de crescimento dos pites associados com os aspectos microestruturais da liga no estado recebida e tratada, após serem submetidos a diferentes tempos de exposição em névoa salina. 


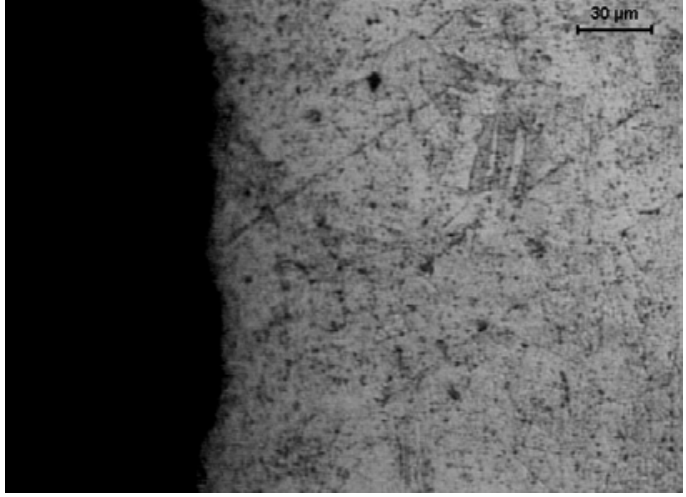

Figura 4 (a): A ocorrência da corrosão por pites no aço inoxidável 310S, no estado como recebida.

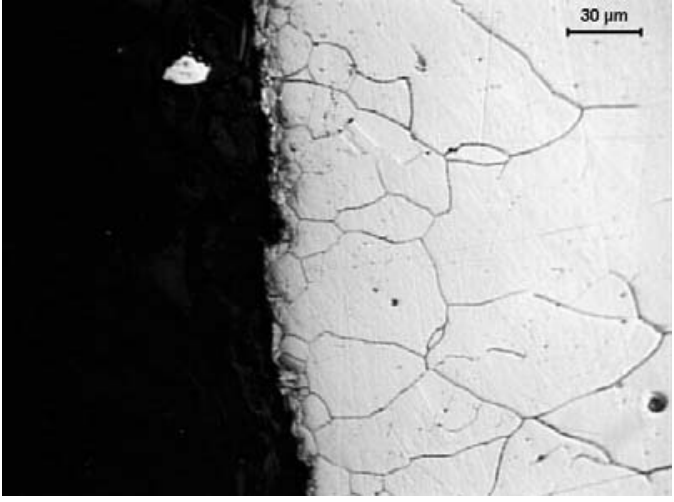

Figura 4 (b): A ocorrência da corrosão por pites no aço inoxidável $310 \mathrm{~S}$, tratado a $620^{\circ} \mathrm{C}-24$ horas e resfriada ao ar.

A formação da corrosão por pites no aço inoxidável AISI 310S revelam diferenças, por meio da associação com a morfologia, distribuição, tamanho e tendência de crescimento dos pites e sua interface microestrutural. A evolução da corrosão por pites possui similaridades quanto a outros aços inoxidáveis tanto como o material no estado como recebido ou tratado, a microestrutura deformada torna-se uma barreira na formação e o crescimento dos pites.

Entretanto, no material tratado a formação da corrosão é facilitada pelo processo de sensitização tornando um canal de indução da corrosão por pites favorecido pelo crescimento dos contornos de grãos, aumentando a fração volumétrica dos precipitados de carbetos de cromo e a morfologia circular.

Na Tabela 3, visualiza-se a seguinte distribuição e classificação dos pites: hemisféricos> região de transição $\mathrm{A}>$ região de transição $\mathrm{B}>$ irregulares> cônicos. Os pites são presentes em maior quantidades hemisféricas e na região transição A, não há evolução temporal de pites cilíndricos no sistema.

Tabela 3: Classificação e distribuição das porcentagens de pites no aço inoxidável 310 S, no estado como recebida.

\begin{tabular}{|c|c|c|c|c|c|c|}
\hline $\begin{array}{c}\text { Tempo de } \\
\text { Exposição } \\
\text { [Horas] }\end{array}$ & $\begin{array}{c}\text { Pites } \\
\text { Irregulares }\end{array}$ & Pites Cônicos & $\begin{array}{c}\text { Pites } \\
\text { Trans A }\end{array}$ & Pites Hemisf. & $\begin{array}{c}\text { Pites } \\
\text { Trans B }\end{array}$ & $\begin{array}{c}\text { Pites } \\
\text { Cilíndricos }\end{array}$ \\
\hline 48 & 0 & 0 & 27 & 22,5 & 50,5 & 0 \\
\hline 120 & 8,76 & 4,25 & 21,13 & 36,30 & 28,06 & 1,50 \\
\hline 168 & 6,50 & 7,60 & 25,44 & 36,66 & 23,80 & 0 \\
\hline 216 & 2,12 & 0 & 16,73 & 21,60 & 59,55 & 0 \\
\hline 312 & 12,82 & 4,22 & 29,03 & 31,35 & 22,58 & 0 \\
\hline
\end{tabular}

Na Tabela 4, visualiza-se a seguinte distribuição e classificação dos pites: região de transição A> hemisféricos> região de transição B > irregulares> cônicos. Os pites são presentes em maior quantidade na região transição A e hemisféricos, não há evolução temporal dos pites cilíndricos no sistema.

Tabela 4: Classificação e distribuição das porcentagens de pites no aço inoxidável 310 S, tratada a $620^{\circ} \mathrm{C}-24$ Horas e resfriamento ao ar.

\begin{tabular}{|c|c|c|c|c|c|c|}
\hline $\begin{array}{c}\text { Tempo de } \\
\text { Exposição } \\
\text { [Horas] }\end{array}$ & $\begin{array}{c}\text { Pites } \\
\text { Irregulares }\end{array}$ & Pites Cônicos & $\begin{array}{c}\text { Pites } \\
\text { Trans A }\end{array}$ & Pites Hemisf. & $\begin{array}{c}\text { Pites } \\
\text { Trans B }\end{array}$ & $\begin{array}{c}\text { Pites } \\
\text { Cilíndricos }\end{array}$ \\
\hline 48 & 0 & 0 & 18,14 & 24,29 & 55,14 & 2,43 \\
\hline 120 & 3,17 & 2,08 & 27,09 & 31,43 & 39,26 & 0 \\
\hline 168 & 15,87 & 2,59 & 26,98 & 29,16 & 25,40 & 0 \\
\hline 216 & 6,44 & 13,30 & 61,80 & 15,88 & 2,58 & 0 \\
\hline 312 & 12,30 & 6,56 & 39,33 & 24,60 & 17,21 & 0 \\
\hline
\end{tabular}

A Tabela 5, apresenta a seguinte ordem no tamanho da mediana da largura e profundidade dos pites associada com a morfologia: irregulares $>$ cônicos $>$ transição A> hemisféricos $>$ transição B; não foi observada a existência de pites cilíndricos no sistema para o aço inox 310S. 
A geometria dos pites aparenta-se: maior na largura (ordem de 6 vezes) que na profundidade e cresce preferencialmente na largura. Observa-se que quanto maior tempo de exposição na condição como recebido, maior a largura dos pites mesmo entre as diferentes morfologias (irregulares: 37,87 $\mu \mathrm{m}$ e cônicos: 8,26 $\mu \mathrm{m}$ em 312 horas e irregulares: 19,30 $\mu \mathrm{m}$ em 120 horas e 37,87 $\mu \mathrm{m}$ em 312 horas) e a profundidade constante.

Tabela 5: Mediana da largura e profundidade dos pites no aço inoxidável 310 S, como recebido.

\begin{tabular}{|c|c|c|c|c|c|c|c|}
\hline $\begin{array}{c}\text { Tempo de } \\
\text { Exposição } \\
\text { [Horas] }\end{array}$ & $\begin{array}{c}\text { Parâmetros } \\
\text { [mediana] } \\
\boldsymbol{\mu m}\end{array}$ & $\begin{array}{c}\text { Pites } \\
\text { Irreg }\end{array}$ & $\begin{array}{c}\text { Pites } \\
\text { Cônicos }\end{array}$ & $\begin{array}{c}\text { Pites } \\
\text { Trans A }\end{array}$ & $\begin{array}{c}\text { Pites } \\
\text { Hemisf. }\end{array}$ & $\begin{array}{c}\text { Pites } \\
\text { Trans B }\end{array}$ & $\begin{array}{c}\text { Pites } \\
\text { Cilíndricos }\end{array}$ \\
\hline 48 & $\begin{array}{c}\text { Largura } \\
\text { Profundidade }\end{array}$ & 0 & 0 & 4,54 & 5,53 & 9,17 & 0 \\
\hline 120 & Largura & 19,30 & 13,70 & 14,51 & 10,97 & 6,38 & 5,08 \\
& Profundidade & 5,73 & 4,97 & 4,99 & 4,44 & 4,82 & 4,72 \\
\hline 168 & Largura & 37,78 & 0 & 15,41 & 13,10 & 6,43 & 0 \\
& Profundidade & 6,15 & 0 & 4,21 & 3,93 & 4,59 & 0 \\
\hline 216 & Largura & 13,77 & 0 & 5,01 & 15,41 & 6,43 & 0 \\
& Profundidade & 6,16 & 0 & 6,72 & 4,21 & 4,59 & 0 \\
\hline 312 & Largura & 37,87 & 8,26 & 11,62 & 7,55 & 5,27 & 0 \\
& Profundidade & 6,41 & 6,90 & 5,08 & 4,98 & 5,19 & 0 \\
\hline
\end{tabular}

Na Tabela 6, apresenta-se a seguinte ordem na mediana do tamanho na largura e profundidade associada com a morfologia dos pites: irregulares> cônicos> transição A> hemisféricos> transição B>cilíndricos.

Tabela 6: Mediana da largura e profundidade dos pites no aço inoxidável $310 \mathrm{~S}$, tratada a $620^{\circ} \mathrm{C}-24$ Horas e resfriamento ao ar.

\begin{tabular}{|c|c|c|c|c|c|c|c|}
\hline $\begin{array}{c}\text { Tempo de } \\
\text { Exposição } \\
\text { [Horas] }\end{array}$ & $\begin{array}{c}\text { Parâmetros } \\
\text { [mediana] } \\
\boldsymbol{\mu m}\end{array}$ & $\begin{array}{c}\text { Pites } \\
\text { Irreg }\end{array}$ & $\begin{array}{c}\text { Pites } \\
\text { Cônicos }\end{array}$ & $\begin{array}{c}\text { Pites } \\
\text { Trans A }\end{array}$ & $\begin{array}{c}\text { Pites } \\
\text { Hemisf. }\end{array}$ & $\begin{array}{c}\text { Pites } \\
\text { Trans B }\end{array}$ & $\begin{array}{c}\text { Pites } \\
\text { Cilíndricos }\end{array}$ \\
\hline 48 & $\begin{array}{c}\text { Largura } \\
\text { Profundidade }\end{array}$ & 0 & 0 & 4,37 & 3,24 & 4,79 & 4,72 \\
& Largura & 6,65 & 4,86 & 5,71 & 4,97 & 5,10 & 0 \\
& Profundidade & 7,15 & 30,62 & 9,65 & 8,33 & 6,01 & 0 \\
\hline 120 & Largura & 6,35 & 5,01 & 4,17 & 5,01 & 5,12 & 0 \\
& Profundidade & 27,79 & 19,60 & 13,43 & 9,48 & 6,14 & 0 \\
\hline 216 & Largura & 7,04 & 6,30 & 6,16 & 5,54 & 5,19 & 0 \\
& Profundidade & 7,15 & 6,46 & 6,08 & 5,59 & 3,98 & 0 \\
\hline 312 & Largura & 6,96 & 6,35 & 5,80 & 4,88 & 4,92 & 0 \\
& Profundidade & 12,84 & 8,78 & 7,91 & 7,00 & 4,71 & 0 \\
\hline
\end{tabular}

Os pites apresentam-se mais profundos (ordem de 3 vezes) que largos e crescem preferencialmente na profundidade. Nota-se que quanto maior tempo de exposição, maior a profundidade dos pites mesmo entre as diferentes morfologias dos pites (irregulares: 27,79 $\mu \mathrm{m}$ e cônicos: 19,60 $\mu \mathrm{m}$ em 216 horas e irregulares: 7,15 $\mu \mathrm{m}$ em 120 horas e $27,79 \mu \mathrm{m}$ em 216 horas) e a largura constante.

\section{CONCLUSÕES}

A liga após o tratamento térmico de sensitização apresenta a formação de carbetos de cromo no interior e contornos dos grãos, especificamente o aço inoxidável 310S, demonstra-se maior quantidade e mudanças microestruturais, contribuindo para o aumento da corrosão por pites, conforme os dados obtidos na análise dos perfis dos pites.

Na análise dos perfis no aço inoxidável 310S como recebida exibe a seguinte ordem na morfologia dos pites: hemisféricos > região de transição $\mathrm{A}>$ região de transição $\mathrm{B}>$ irregulares $>$ cônicos, sendo que os pites são presentes em maiores quantidades em hemisféricos e na região de transição A. Os pites são mais largos que profundos, crescem preferencialmente na largura. Os pites cilíndricos não foram observados no sistema. Quando a liga é tratada, a cada tempo de exposição apresenta mesma ordem na quantidade de pites: região de transição B $>$ hemisféricos > região de transição A > cônicos > irregulares, particularmente os pites são mais profundos que largos. 
As mudanças significativas na distribuição morfológica e no tamanho dos pites no aço inoxidável 310S quando tratados encontra-se correlacionado com a função dos precipitados de carbeto de cromo, especificamente na quantidade e morfologia. Por meio da análise do tamanho da largura e profundidade dos pites revelam-se a seguinte ordem: irregulares >cônicos > região de transição A > hemisféricos > região de transição B.

No aço inox 310S no estado como recebida e tratado, o comportamento de crescimento dos pites na largura e profundidade são diferentes, sobretudo os valores encontrados na tratada são maiores e altera-se com o tempo de exposição com os valores encontrados nos pites irregulares, na região de transição A e B.

\section{AGRADECIMENTOS}

Os autores agradecem a todos os funcionários da EEL-USP-DEMAR e das Faculdades Integradas Teresa D`Ávila - FATEA. A CONFAB S. A. pelo fornecimento das chapas de aço inoxidável ABNT 310S e a TEKNO S.A. unidade de Guaratinguetá pela realização dos testes de corrosão. Ao PROAP - CAPES e a UNESP - Campus de Guaratinguetá pelo apoio oferecido durante a realização do trabalho.

\section{BIBLIOGRAFIA}

[1] CODARO, E.N., NAKAZATO, R.Z., HOROVISTIZ, A.L., RIBEIRO, L.M.F., RIBEIRO, B., HEIN, L.R.O., "An image processing method for morphology characterization and pitting corrosion evalution", Material Science and Engineering A, v. 334, n. 1-2, pp. 298, 2002.

[2] CODARO, E.N., NAKAZATO, R.Z., HOROVISTIZ, A.L., RIBEIRO, L.M.F., RIBEIRO, B., HEIN, L.R.O., “An image analysis of pit formation on Ti-6Al-4V”, Material Science and Engineering A, v. 341, pp. 12202, 2003.

[3] CODARO, E.N., NAKAZATO, R.Z., HOROVISTIZ, A.L., RIBEIRO, L.M.F., RIBEIRO, B., HEIN, L.R.O., "Evaluation of pitting morphology of Ti-6Al-4V after corrosion testing", XVIII Congresso da Sociedade Brasileira de Microscopia e Microanálise, pp. 135-136, 2001.

[4] SHTZ, E., BERGER, F., BARILLON, R., AUDEBERT, P., CHAMBAUDET, A., "Behaviour of painted mirrors during exposure tests to salt spray”, Applied Surface Science, v. 120, pp. 106-118, 1997.

[5] SPAHN, H., "Performance requirements for stainless steels in the chemical process industry”, Stainless Steel 77, R.Q. Barr, London, 1977.

[6] SZLARSKA-SMIALOWSKA, Z., "Pitting corrosion of metals", National Association of Corrosion Engineers, pp. 281, 1986.

[7] OLIVEIRA, J.C., CAVALEIRO, A., BRETT, C.M.A., "Influence of sputtering condition on corrosion of WTi-N thin film hard coatings: salt tests and image analysis”, Corrosion Science, v. 42, pp. 1881-1895, 2000.

[8] TSAI, T.W., HUANG, K.E., "Microstructural aspect and oxidation resistance of an aluminide coating on 310S stainless steel”, Thin Solid Films, v. 366, pp.164-168, 2000.

[9] ASTM Standard B117, “Standard practice for operation salt spray (fog) apparatus”, v. 3, n. 2, August 1997.

[10] ASTM Standard E1382, "Standard test methods for determining average grain size using semiautomative image analysis”, v. 3, n. 1, July 1997.

[11] RIBEIRO, R.B., Análise morfológica de pites em aços inoxidáveis ABNT 304 e 310 submetidos a exposição em névoa salina, Tese de D.Sc., Universidade Estadual Paulista, UNESP, Guaratinguetá, Brasil, 2004.

[12] MURR, L.E., ADVANI, A., ATTERIDGE, D.G., "Effects of deformation (strain) and heat treatment on grain boundary sensitization and precipitation I austenitic stainless steels”, Materials Characterization, v. 24, pp. 135-138, 1990. 
[13] CARDOSO, R.J.C., MACHADO, A.T., "Estudos de causas de falhas em serviço de tubulação de aço inoxidável AISI 304 de alta pressão", Congresso Brasileiro de Engenharia e Ciências dos Materiais XVI - CBECIMAT, Natal, pp. 357-368, 2002.

[14] MACHADO, I.F., Transformações de fase no estado sólido em alguns aços inoxidáveis e ferríticosausteníticos (dúplex) contendo atos teores de nitrogênio, Tese de D.Sc., Escola Politécnica, Universidade de São Paulo, Brasil, 1999. 